\title{
A Study on Measures of Preservation of Cultural Heritage of Chinese Folk Music
}

\author{
Yibin Wang \\ Art College\& Post Doctorate of Management \\ Xiamen University \\ P. R. China \\ e-mail: wyb119@126.com
}

\begin{abstract}
Musical heritage is the most stable section in the cultural sediment, which is free from the impact of time and space. Hence the music from Chinese ancestors recorded in the historical literature thousands of years ago can come into the horizon of the researchers vividly. From the late of the 20th century on, the prosperity of the processing-oriented township industry and tourism injected vitality into the rural economy in China, resulting in not only the increase of peasants' income and improvement of their life but also the transformation of their living space and concept. As a result, the inheritance and development of traditional folk music are inevitably subject to the influence of this situation. Confronting the outside impact and partial extinction involving the intangible folk cultural heritage, many scholars set out to go deep into the rural areas and make an investigation, advancing such preservation measures as "museum-style", a measure by establishing museums to preserve cultural heritage, in an attempt to preserve the splendid cultural heritage on the verge of extinction. Based on the characteristics of current survival state of Chinese folk musical heritage and the previous preservation modes, this paper proposes a new concept "preserve heritage by means of exploiting it" in accordance with law of the development of things and spirit of marching with the times in an attempt to find a fundamental solution in protecting and developing traditional musical heritage and traditional culture at large.
\end{abstract}

Keywords-Musical heritage; Music of mixed forms; Preserve heritage

\section{INTRODUCTION}

In various archeological scenes, the process of excavating the land will remind archeologists the clear recollections about history, the change of which is recorded by the layered soil. We can get some physical perception from the remained underground world by sense. Accordingly, we can also understand the social culture existed in human beings' spirits, even though the culture does not appear outwardly or formally. It is because in the process of evolution, all kinds of cultures and traditions have their marks in the society, which people can only perceive by their wisdom and patience. Correspondingly, the accumulation of cultures appears more deeply and profound. Such as the songs in Papua New Guinea, it is said that this was sung in a wailing manner by the spirit of a dead elder brother who appeared in his drowsy younger brother's dream, asking "Carry away my body quickly to the grave", when all those concerned gathered and were singing wept-songs at midnight. The younger brother awaking from his sleeping, immediately sang that tune, and went out to bury his elder brother's corpse before dawn. This occurrence took place about two generations ago[1]. Since the musical heritage is one of the steadiest parts in the accumulation of cultures, it can continue to exist during the thousands of years. Thus the loomed music of ancestors will appear vividly before those researchers in the end. By a close examination, however, we feel worried about the survival of the excellent folk music heritage, for the fact that with the acceleration of industrialization and modernization, the town industry and tourism bring a new opportunity to our rural economy, increasing the income of peasants, somewhat improving their lives, what's more, changing their living space and conception, and affecting the succession and development of folk music heritage. Even to the extent, the song to the Flying Fox is part of the larger song cycle of the Yagun association. In the performance of this song cycle during a major death ceremony it is the forty-ninth song performed by one singer. [2]

\section{The State of Survival of the Cultural Heritage CONCERNING CHINESE FolK MUSIC}

It gives no cause for more criticism that researchers seem to prefer searching for history in literature. But one day if you put down those old documents and go out for a sight you are sure to be surprised by the living force of those stalwart country people and filled with admiration for those folk music, such as folk music of the minority Bai in Jianchuan of Yunnan Province, the local music of Guizhou Province and so on. Comparing with an individual life, the folk music appears to be of so long standing. For example, the rise and fall of the minority Miao can be indicated from enjoying a musical instrument "Lu Sheng"; a ballad of the minority Dong will tell the listener where their ancestors come. And according to the status of ancient musical heritage, it can be divided into music of original forms, music of mixed forms, and music of new forms, etc.

The music of original forms, an original state of survival, refers to the state that the music is passed on from ancient period and continues to be developed and inherited by the admissive people, in a special form, by its intrinsic way, and in a relatively closed space. The most distinguished feature of 
this kind of music is invariability, i.e. since its content was rooted from some ancient music according to the historical recordation it is changeless, and its form is also seldom changed by outside world. And this kind of music bears strong religious characteristic with the representation of deity adoration, which shows the release of human beings' spirits, and is an ideal situation where people can get rid of those troubles in reality. The musical heritage of original forms, maintaining our historical musical tradition, is helpful and instructional for us to learn ancient musical culture, and to rewrite the ancient history of musical culture. For instance, the song Pan of the Minority Yao not only narrates the history of the King of Pan and the Minority Yao, but also has a high value for research of the ancient folk song. Here comes another example: a kind of local drama Nuo, distributed in the south of China, is a heritage of the ancient culture of Wu'nuo. It took the characteristics and styles-the primitive simplicity and vigorousness-of Nan'xi from Song and Yuan dynasty. And it accordingly is considered the living fossil of the drama and music in China. Of course, it is also clear that foreign ethnomusicologists are far from being the only interventionists, and there is in principle no reason why ethnomusicologists should not use their training and awareness to intervene effectively. ${ }^{[3]}$

The music of mixed forms refers to those maintained original music, combined with some certain modern assistant elements on the basis of some special contents, developed by admissive people on special occasions, after experiencing the great change of social politics, economy and culture. Contrasting with the music of original forms, this mixed music is not in a closed space any more, and it takes modern elements to make some alteration in the form and content, but the alteration does not exist in the core of this kind of music, i.e. the essence of this art does not change. This mixed music bears no religious feature but functions as an entertainment, which does not have the direct commercial value. For example, Nanqu in Fujian Province syncretized the musical elements after Tang and Song dynasty, forming a special local feature, called the living history of music. This music can be enjoyed by some amateurs, singing at home or a corner in a park; it can also be performed by the professional players and singers in a theater to show the simple and elegant style of this art. What's more, the League of Nanqu Performance in Fujian Province often go abroad to perform this kind of art in order for the inter-cultural communication and the mutual trade development.

The music of new forms refers to those arts which can be performed in different occasions anytime to get the material gain or the commercial value, base on the maintained ancient music, combined with relevant art elements of various periods, manifesting the different content and forms from the original music. Broken away from the simple psychological value of the original musical art, this kind of music exists for the pursuit of the commercial profit and for enjoying the audience. In September, 2002, the author saw two Naxi performance groups of the ancient music in the competition of attracting the audience in Lijiang City of Yunnan Province in order to gain more money since their performance should be paid to watch. Thus, the ancient music performance is connected with the local tourism economy. The audience, however, cannot understand the Naxi music deeply because what they see is just the form of the music, so that they cannot imagine the war between the Minority Naxi and other nationalities when hearing the song "Bai Sha Xi Yue".

\section{The Measures of Preservation Cultural Heritage of ChINese FolK Music}

As the intangible cultural property was destroyed and the inheritance of folk music gradually died away, some researchers went to the countryside to study the folk music. In reference to the preservation measures taken by other countries, they proposed such measures as "museum preservation", aiming at preserving and rescuing the folk music from extinguishing. However, the measures taken only by a minority of researchers cannot solve the problem that a variety of folk inheritance is on the edge of extinction.

This paper is based on a study of the different surviving stages of Chinese folk music, that is, the original stage, the mixed-up stage, and the new form stage. On the basis of the existing "closed" and "museum" preservation measures, the author puts forward a new concept of "preserving inheritance with inheritance", which is in accordance with the development of folk music, and which is attempted to cultivate essential lands for the preservation and development of folk music and even for folk culture. With the same situation, the nose flute in Melanesia is most likely a Micronesian influence (Friederici mentiongs nose-blown flutes among the Bariai and other references come from the southeast coast of New Guinea and the northeastern part of Papua, from Bentley Bay and Normanby Island, from the mainland near Mailu). The instrument types can only be inferred from Saville's report, according to which the usual end-blown flute with fingerholes is blown either with the mouth or with the nose. MacGregor, on the other hand, talks of a side-blown nose flute. ${ }^{[4]}$

"Close preservation" is to confine the folk music to a closed environment so as not to be affected by the outside world. As the preservation requires a rigid "vacuum" surrounding, the inheritance of folk music is temporarily preserved at the cost of myths, political, economic and cultural development. Myths about the origin of the drum almost exclusively have then originating from spirit beings, in contrast to the explanatory myths for "spirit voice" instruments. ${ }^{[4]}$

"Museum-style" is concerning the extinguished or would-be distinguished music culture heritage. Now that it cannot survive in original surroundings, it must be removed to artificial surroundings in order to obtain a perfectness of the style. In practice, the moving from living folk music culture to museums indicates the death of its vitality.

"Preserving heritage by means of exploiting it", seen from the rural social development and economic state, "confining-style preservation" is not permitted by the local people. Development is a settled social tendency; it goes against the social developing rules to hold back the loss of traditional culture by sacrificing the local development and 
leaving the local people in a relatively underdeveloped living conditions. "Museum-style" is to create an artificial scene of "imitation of original culture" leave the living local music culture in a static state, while is what the rural economic power cannot bear and contrary to the developing rules of heritage itself.

According to the statistic and analysis of rural economic green book and economic blue book, the income of Chinese peasants is increasing more and more slowly in 2000 and 2001. Agricultural income, especially the income of plantation is decreasing continuously. The peasants' average income is 2253 Yuan (RMB) in 2000, increasing by 1.9 percent. It mostly resulted from the salary of outside peasant workers. But peasants' average expenditure was 1670 Yuan (RMB), increasing by 5 percent. Most peasants have food to eat but no money to spend. So the green book and the blue book suggest labor economy, rearrangement of rural economic and organizing structure, quickening the shift of rural labors, relieving peasants' burden, increasing peasants' income and living standard.

Martin Heidegger was sure that, as for a tradition of thoughts, the power of salvage can only come from itself, from its endeavor to trace back to the conformity of thought and history. As to a nation or a tradition, origin and basis have their inside historicity; Fate and salvage also have their inside history. Only one God can save us.

Under the current political and economic state of China, the feasible way to avoid the extinction of folk music is to enhance the project of "preserving heritage by means of exploiting it" and to bring it into line of the state plan.

The government takes part in the construction and management. The local government invests firstly and brings the musicals culture construction into line of the whole local plan.

The local tourist institutions exploit invisible cultural property, combine human and natural landscape and incorporate musical cultural heritage into tourist projects.

Folk musical heritage adopts the strategy of survival of two heritages. On one hand, part of the members is departed from the heritage to take the jobs of performance and propaganda; and on the other hand, the other members take the original life style of the heritage. The later is supported by the former's income, which is "preserving heritage by means of exploiting it".

\section{CONCLUSIONS}

By and large, China is a country with a civilization stretching back five thousand years and rich musical cultural heritage. Chinese folk music, a significant part of Chinese culture, not only fully reflects the development of Chinese musical culture, but influences the spiritual civilization of the entire humanity. However, "museum-style" and "closed-style, the 2 widely-adopted methods, failed to provide it with proper preservation. What was worse, they were likely to strangle its vitality and authenticity of Chinese folk music. "Preserving heritage by means of exploiting it" is a scientific and sustainable approach to preserve Chinese folk music with the maintenance of its primitiveness and adaption to economic growth. It can retain the original spirit of Chinese folk music, and encourage moderate innovation. It allows local people to enjoy a better quality of life without disrupting the way they live. By this method, Chinese folk music, the intangible and endangered cultural heritage, can be well preserved and carried on.

\section{REFERENCES}

[1] Yamada, Yoichi, Songs or Sprits: An Ethnography of Sounds in a Papua New Guinea Society, Institute of Papua New Guinea Studies, 1997, 41.

[2] Wassmann, Jürg, The Song to the Flying Fox, Cultural Studies Division The National Research Institute, 1991, 255.

[3] Stock, Jonathan P.J. Huju: Traditional Opera in Modern Shanghai. The British Academy by Oxford University Press, 2003, 207.

[4] Fischer, Hans. Sound Producing Instruments in Oceania, Institute of Papua New Guinea Studies, 1986, p103-10. 